\title{
Predictors for Depressive Mood in Geriatric Patients After Traumatic Brain Injury: A Retrospective Cross-Sectional Study
}

\author{
Je Kyung Kim, MD, Na Young Kim, MD, Yong Wook Kim, MD, PhD
}

Department of Rehabilitation Medicine and Research Institute of Rehabilitation Medicine, Yonsei University College of Medicine, Seoul, Korea

\begin{abstract}
Objective To identify predictors for depressive mood in geriatric patients after traumatic brain injury (TBI). Methods A retrospective review of patients' medical charts was performed in TBI patients who were older than 60 years and referred to the Department of Rehabilitation Medicine at Severance Hospital in 2002-2016. The patients were classified into two groups based on the Geriatric Depression Scale (GDS): non-depressive group ( $0 \leq$ GDS $\leq 16$ ) and depressive group ( $17 \leq \mathrm{GDS} \leq 30)$. Data was collected on demographic, socioeconomic, comorbidities, and trauma-related factors, as well as the pathophysiology of TBI, localization of lesion, post-traumatic complications, functional level, and cognitive and linguistic function. Significant variables from univariate analysis were analyzed using logistic regression.

Results Forty-two patients were included, of whom $64.3 \%$ displayed a depressive mood. Patients in the depressive group had higher comorbidity scores $(\mathrm{p}=0.03)$, lower Functional Independence Measure (FIM) totals ( $\mathrm{p}=0.03)$ and FIM motor ( $\mathrm{p}=0.03$ ) scores, higher modified Rankin Scale scores $(\mathrm{p}=0.04)$, and frequently had a bilateral or left side brain lesion ( $\mathrm{p}=0.002$ ). Higher comorbidity scores (odds ratio [OR], 1.764; 95\% confidence interval [CI], 1.047 2.971), bilateral lesions (OR, 13.078; 95\% CI, 1.786-95.780), and left side lesions (OR, 46.074; 95\% CI, 3.175-668.502) were independently associated with a depressive mood in the multiple logistic regression analysis.

Conclusion The risk of depressive mood in geriatric patients after TBI is associated with comorbidity, functional limitation, and the horizontal distribution of brain lesions. The most significant determining factors were comorbidity and the horizontal distribution of brain lesions. Early detection of risk factors is important to prevent and manage depressive mood in geriatric patients after TBI.
\end{abstract}

Keywords Depression, Geriatric, Brain injuries, Risk factors

Received June 24, 2016; Accepted August 18, 2016

Corresponding author: Yong Wook Kim

Department of Rehabilitation Medicine and Research Institute of Rehabilitation Medicine, Yonsei University College of Medicine, 50-1 Yonsei-ro, Seodaemun-gu, Seoul 03722, Korea. Tel: +82-2-228-3716, Fax: +82-2-363-2795, E-mail: ywkim1@yuhs.ac

ORCID: Je Kyung Kim (http://orcid.org/0000-0001-9482-4905); Na Young Kim (http://orcid.org/0000-0001-9888-3953); Yong Wook Kim (http://orcid. org/0000-0002-5234-2454).

() This is an open-access article distributed under the terms of the Creative Commons Attribution Non-Commercial License (http://creativecommons.org/ licenses/by-nc/4.0) which permits unrestricted noncommercial use, distribution, and reproduction in any medium, provided the original work is properly cited. Copyright $\odot 2017$ by Korean Academy of Rehabilitation Medicine 


\section{INTRODUCTION}

Depressive mood is a common and important problem after traumatic brain injury (TBI). Post-traumatic depression has been linked to decreased motivation to participate in rehabilitation, as well as with unfavorable outcomes, including reduced quality of life, increased health-related impairment, decreased employment and community integration, and increased risk of suicide [1-3]. Previous research has found the prevalence of depressive mood in the overall TBI population to vary from $15.3 \%$ to $42 \%[2,4]$, which is a 7.5 -fold increase compared with the prevalence in the general community population [2]. The variability in assessment methods and in subject severity of disease and onset duration after injury has contributed to differing descriptions of depression in TBI patients.

TBI has a bimodal distribution, with the peak ages being young adults and the elderly population [5]. Since the proportion of the elderly in the general population is rapidly increasing, the number of post-traumatic elderly patients is also rapidly increasing. Generally, because elderly TBI patients present with disorder of consciousness and severe cognitive deficit with lower functional status, old age has been identified as one of the strongest and best documented predictors for poor outcome and high mortality in TBI [6-8].

Previous studies reported that the prevalence of mood disorder in the elderly TBI population ranges from $21 \%$ to $37 \%[2,9]$. Considering that the prevalence of depressive mood has been reported to be $1.8 \%-8.9 \%$ in communityresiding elders and $25 \%$ in nursing homes and long-term care settings, depressive mood in post-traumatic elderly patients is remarkably high [2]. However, there are few studies on the predictors of depressive mood in elderly TBI patients. Therefore, the aim of this study was to analyze the association between the clinical data of geriatric TBI patients and the occurrence of depressive mood, and to identify predictors for the development of depressive mood in geriatric patients after TBI.

\section{MATERIALS AND METHODS}

\section{Subjects}

Data were retrospectively collected from the medical records of patients diagnosed with TBI and hospitalized in the Department of Rehabilitation Medicine at Severance Hospital from January 1, 2002 to April 30, 2016. The inclusion criteria were (1) patients with TBI diagnosed with a neuroimaging study (brain CT or MRI), neurological examination and history of disease; (2) patients who experienced TBI for the first time; and (3) patients aged over 60 years. Exclusion criteria were: (1) patients with disorder of consciousness (vegetative state or minimally conscious state); (2) patients with severe cognitive deficit using the Korean version of Mini-Mental Status Examination (K-MMSE) scores < 10 points; and (3) patients with any previous history of neuropsychiatric disorders diagnosed before brain injury.

\section{Demographic and socioeconomic data}

The demographic and socioeconomic data including age, sex, handedness, education level, and urbanity were evaluated. We used the Edinburgh Handedness Inventory for assessment of handedness [10]. The education level was categorized into 5 groups by the total years of education as $<6$ years, $\geq 6$ and $<9$ years, $\geq 9$ and $<12$ years, $\geq 12$ and $<16$ years, and $\geq 16$ years. The urbanity, living in an urban area, was defined as living in towns of 50,000 inhabitants or more.

\section{Comorbidities}

To evaluate the comorbidities of our subjects we used the comorbidity score of the Charlson Comorbidity Index $[11,12]$ which indicates both the number and the seriousness of comorbid diseases. It has been used to account for the impact of comorbid conditions on outcomes in ischemic stroke [13] and geriatric traumatic brain injury [14]. The weighted points for each medical condition were summed to obtain the comorbidity score. The assigned weighted points for diseases were: one point for myocardial infarction, congestive heart failure, peripheral vascular disease, cerebrovascular disease, dementia, chronic obstructive pulmonary disease, connective tissue disease, peptic ulcer disease, uncomplicated diabetes, and mild liver diseases; two points for hemiplegia, moderate to severe chronic kidney disease, diabetes with end organ damage, any solid tumor, and leukemia and lymphoma; three points for moderate to severe liver disease; and six points for metastatic solid tumor and acquired immune deficiency syndrome (AIDS). 


\section{Trauma related factors}

The onset duration after the injury, injury mechanism (motor vehicle accident, fall, and others), and the presence of loss of consciousness at the time of the injury were investigated.

Pathophysiology of brain injury and localization of lesion Brain CT or MRI findings were reviewed by a neuroradiologist with more than 3 years of clinical experience. The pathophysiology of brain injury was classified by contusional hemorrhage and contusional hemorrhage with diffuse axonal injury. The TBI lesion location was categorized for vertical distribution by isolated supratentorial lesion or supratentorial lesion with infratentorial lesion, and for horizontal distribution by right hemispheric, left hemispheric, and bilateral hemispheric lesions.

\section{Post-traumatic complications}

Information was recorded on the post-traumatic complications including dysphagia (the presence of aspiration on videofluoroscopic swallowing study), pain (neuropathic pain, musculoskeletal pain, and mixed type), open neurosurgery, seizure, hydrocephalus with ventriculoperitoneal shunt, skull fracture, and skeletal fracture.

\section{Linguistic function, cognitive function, functional status,} and disability level

Linguistic function was tested in all subjects by assessing the presence of dysarthria and aphasia quotient measured by the Korean version of the Western Aphasia Battery (K-WAB), and the naming ability by the Korean Boston Naming Test (K-BNT) [15]. The K-MMSE score was used to assess the cognitive function of each subject. The Functional Independence Measure (FIM) is a tool to assess the independency on activities of daily living, with a total score of 126 points, and 13 items that define motor function disability (FIM-motor), and 5 items that define cognitive function disability (FIM-cog) [16]. The Functional Ambulation Classification (FAC) was used to measure the ambulatory ability of the subjects [17]. The degree of disability of each subject was classified by the modified Rankin Scale (mRS) [18].

\section{Evaluation of depressive mood}

Depressive mood was evaluated using the Geriatric Depression Scale (GDS) score. This scale consisted of 30 yes-or-no questions, with one point scored for yes and 0 point scored for no, for a total of 30 points. Scores $\geq 17$ points have been reported to indicate a high possibility of major depressive disorder. The patients were classified into two groups according to a cut-off score of 17 in order to identify the correlation between depressive mood and clinical factors (non-depressive group, $0 \leq \mathrm{GDS} \leq 16$; depressive group, $17 \leq \mathrm{GDS} \leq 30$ ) [19].

\section{Statistical analyses}

SPSS ver. 22.0 (IBM SPSS Inc., Armonk, NY, USA) was used for statistical analyses. The association between depressive mood and categorical variables, including sex, handedness, education level, urbanity, injury mechanism, loss of consciousness, pathophysiology of brain injury, vertical distribution, horizontal distribution, dysphagia, pain, open neurosurgery, seizure, hydrocephalus, ventriculoperitoneal shunt, skull fracture, skeletal fracture, dysarthria, FAC level, and mRS score, were assessed by using the $\chi^{2}$ test and Fisher exact test. The Mann-Whitney U-test was used for continuous variables such as age, comorbidity score, onset duration after injury, aphasia quotient, K-BNT score, K-MMSE score, and FIM score. In order to identify the risk factors for depressive mood, a binary logistic regression model was used. Statistical significance was assigned at $\mathrm{p}<0.05$.

\section{RESULTS}

Among the 126 patients older than 60 years with first TBI, 42 patients were recruited by the inclusion and exclusion criteria, as shown in Fig. 1. We classified 15 subjects (35.7\%) into the non-depressive group and 27 subjects (64.3\%) into the depressive group (Fig. 1).

\section{Depressive mood in relation to demographic, socioeconomic data, and the comorbidities}

Comorbidity score was significantly higher in the depressive group (depressive group 3.5 \pm 2.1 , non-depressive group 2.1 $\pm 1.7 ; \mathrm{p}=0.03$ ) (Table 1 ). Other factors such as age, sex, handedness, education level, and urbanity did not show significant correlations with depressive mood.

Depressive mood in relation to trauma related factors

There were no significant differences in these factors between the two groups (Table 2). 
Exclusion criteria $(n=60)$

Disorders of consciousness $(n=31)$

Severe cognitive deficit (K-MMSE scores $<10)(n=27)$

Any previous history of neuropsychiatric disorders

diagnosed before brain injury $(n=2)$

Patients $\geq 60$ years diagnosed with traumatic brain injury

$(n=126)$

Failed to meet the inclusion criteria

Not their fist traumatic brain injury $(n=2)$

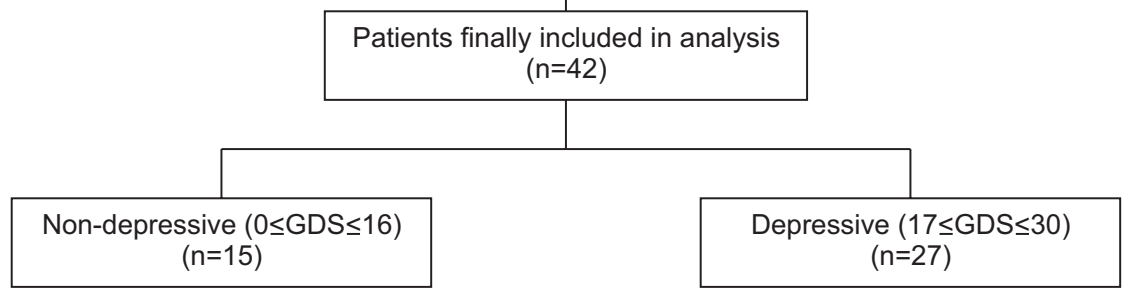

Fig. 1. Flowchart of the subjects. A total of 126 geriatric patients with traumatic brain injury were assessed from January 1, 2002 to April 30, 2016. Finally, 42 patients were included and classified into two groups based on the Geriatric Depression Scale (GDS). K-MMSE, Korean version of Mini-Mental Status Examination.

Table 1. Demographic, socioeconomic data, and the comorbidities of depressive and non-depressive geriatric patients after traumatic brain injury

\begin{tabular}{|c|c|c|c|c|}
\hline Variable & $\begin{array}{c}\text { Total } \\
(n=42)\end{array}$ & $\begin{array}{c}\text { Non-depressive group } \\
(n=15)\end{array}$ & $\begin{array}{c}\text { Depressive group } \\
(\mathrm{n}=\mathbf{2 7})\end{array}$ & p-value \\
\hline Age (yr) & $69.6 \pm 7.1$ & $71.9 \pm 8.1$ & $68.3 \pm 6.3$ & 0.15 \\
\hline Sex & & & & 0.31 \\
\hline Male & $29(69.0)$ & $12(80.0)$ & $17(63.0)$ & \\
\hline Female & $13(31.0)$ & $3(20.0)$ & $10(37.0)$ & \\
\hline Handedness & & & & 1.00 \\
\hline Right handed & $41(97.6)$ & $15(100)$ & $26(96.3)$ & \\
\hline Left handed & $1(2.4)$ & $0(0)$ & $1(3.7)$ & \\
\hline Education years & & & & 0.16 \\
\hline$<6$ & $4(9.5)$ & $0(0)$ & $4(14.8)$ & \\
\hline$\geq 6$ and $<9$ & $8(19.0)$ & $2(13.3)$ & $6(22.2)$ & \\
\hline$\geq 9$ and $<12$ & $6(14.3)$ & $1(6.7)$ & $5(18.5)$ & \\
\hline$\geq 12$ and $<16$ & $13(31.0)$ & $5(33.3)$ & $8(29.6)$ & \\
\hline$\geq 16$ & $11(26.2)$ & $7(46.7)$ & $4(14.8)$ & \\
\hline Urbanity & & & & 0.53 \\
\hline Urban & $40(95.2)$ & $15(100)$ & $25(92.6)$ & \\
\hline Rural & $2(4.8)$ & $0(0.0)$ & $2(7.4)$ & \\
\hline Comorbidity score & $3.0 \pm 2.1$ & $2.1 \pm 1.7$ & $3.5 \pm 2.1$ & $0.03^{*}$ \\
\hline
\end{tabular}

Values are presented as mean \pm standard deviation or number $(\%)$.

${ }^{*} \mathrm{p}<0.05$. 
Table 2. Trauma related factors, pathophysiology of brain injury and localization of lesion of depressive and nondepressive geriatric patients after traumatic brain injury

\begin{tabular}{|c|c|c|c|c|}
\hline Variable & $\begin{array}{c}\text { Total } \\
(n=42)\end{array}$ & $\begin{array}{l}\text { Non-depressive group } \\
(\mathrm{n}=15)\end{array}$ & $\begin{array}{c}\text { Depressive group } \\
(\mathbf{n}=27)\end{array}$ & p-value \\
\hline Days after injury & $130.4 \pm 104.9$ & $164.1 \pm 135.4$ & $111.7 \pm 80.4$ & 0.31 \\
\hline Injury mechanism & & & & 0.59 \\
\hline \multicolumn{5}{|l|}{ Motor vehicle accident } \\
\hline Pedestrian injury & $7(16.7)$ & $1(6.7)$ & $6(22.2)$ & \\
\hline Passenger injury & $6(14.3)$ & $2(13.3)$ & $4(14.8)$ & \\
\hline Motorcycle & $1(2.4)$ & $0(0.0)$ & $1(3.7)$ & \\
\hline Bicycle & $5(11.9)$ & $1(6.7)$ & $4(14.8)$ & \\
\hline Fall & $21(50.0)$ & $10(66.7)$ & $11(40.7)$ & \\
\hline Others & $2(4.8)$ & $1(6.7)$ & $1(3.7)$ & \\
\hline Loss of consciousness (\%) & $20(62.5)$ & $7(53.8)$ & $13(68.4)$ & 0.47 \\
\hline Pathophysiology of brain injury (\%) & & & & 0.14 \\
\hline Contusional hemorrhage without DAI & $37(88.1)$ & $15(100)$ & $22(81.5)$ & \\
\hline Contusional hemorrhage with DAI & $5(11.9)$ & $0(0)$ & $5(18.5)$ & \\
\hline Vertical distribution (\%) & & & & 0.08 \\
\hline Isolated supratentorial lesion & $35(83.3)$ & $10(66.7)$ & $25(92.6)$ & \\
\hline Supratentorial and infratentorial lesion & $7(16.7)$ & $5(33.3)$ & $2(7.4)$ & \\
\hline Horizontal distribution (\%) & & & & $0.002^{*}$ \\
\hline Right & $12(28.6)$ & $9(60.0)$ & $3(11.1)$ & \\
\hline Left & $11(26.2)$ & $1(6.7)$ & $10(37.0)$ & \\
\hline Bilateral & $19(45.2)$ & $5(33.3)$ & $14(51.9)$ & \\
\hline
\end{tabular}

Values are presented as mean \pm standard deviation or number (\%).

DAI, diffuse axonal injury.

${ }^{*} \mathrm{p}<0.05$.

Depressive mood in relation to pathophysiology of brain injury and localization of lesions

The horizontal distribution of lesions was significantly different between the two groups-depressive group, bilateral $(51.9 \%)>$ left hemispheric $(37.0 \%)>$ right hemispheric (11.1\%); non-depressive group, right hemispheric $(60.0 \%)>$ bilateral $(33.3 \%)>$ left hemispheric $(6.7 \%)$; $\mathrm{p}=0.002$ (Table 2). Depressive groups had significantly more bilateral and left hemispheric brain lesions, while non-depressive groups had more right side brain lesions. Other factors in these subgroups showed no statistically significant differences between the two groups.

\section{Depressive mood in relation to post-traumatic complications}

There were no significant differences in these factors between the two groups (Table 3).
Depressive mood in relation to linguistic function, cognitive function, functional status, and disability level

Lower FIM total scores (depressive group 51.8 \pm 24.6 , non-depressive group $70.9 \pm 27.9 ; \mathrm{p}=0.03)$ and low FIM motor scores (depressive group $33.7 \pm 17.8$, non-depressive group 51.4 $\pm 23.8 ; \mathrm{p}=0.03$ ) showed statistically significant associations with depressive mood. Lower FIM cognitive scores (depressive group 17.7 \pm 8.3 , non-depressive group 21.3 $\pm 7.8 ; \mathrm{p}=0.09$ ) had a trend of association with depressive mood, although this association was not statistically significant. Higher mRS scores (depressive group: mRS score $5(51.9 \%)>4(25.9 \%)>3(18.5 \%)>1$ (3.7\%); non-depressive group: mRS score $2(33.3 \%)>3$ $(26.7 \%)>4(20.0 \%), 5(20.0 \%) ; p=0.04)$ also had a statistically significant association with depressive mood (Table 4). Patients with depressive mood showed a tendency of a lower FAC level (depressive group: FAC level 1 (55.6\%) 
Table 3. Post-traumatic complications of depressive and non-depressive geriatric patients after traumatic brain injury

\begin{tabular}{|c|c|c|c|c|}
\hline Variable & $\begin{array}{c}\text { Total } \\
(n=42)\end{array}$ & $\begin{array}{c}\text { Non-depressive group } \\
(\mathrm{n}=15)\end{array}$ & $\begin{array}{c}\text { Depressive group } \\
(n=27)\end{array}$ & p-value \\
\hline Dysphagia & $28(68.3)$ & $10(66.7)$ & $18(69.2)$ & 1.00 \\
\hline Pain & & & & 0.88 \\
\hline Yes & $18(42.9)$ & $5(33.3)$ & $13(48.1)$ & 0.35 \\
\hline Neuropathic pain & $1(2.4)$ & $0(0)$ & $1(3.7)$ & \\
\hline Musculoskeletal pain & $11(26.2)$ & $3(20.0)$ & $8(29.6)$ & \\
\hline Mixed pain & $6(14.3)$ & $2(13.3)$ & $4(14.8)$ & \\
\hline No & $24(57.1)$ & $10(66.7)$ & $14(51.9)$ & \\
\hline Open neurosurgery & $16(38.1)$ & $6(40.0)$ & $10(37.0)$ & 0.85 \\
\hline Seizure & $7(18.4)$ & $3(21.4)$ & $4(16.7)$ & 1.00 \\
\hline \multicolumn{5}{|l|}{ Hydrocephalus } \\
\hline Yes & $13(31.0)$ & $6(40.0)$ & $7(25.9)$ & 0.49 \\
\hline Ventriculoperitoneal shunt & $4(9.5)$ & $2(13.3)$ & $2(7.4)$ & 0.61 \\
\hline No & $29(69.0)$ & $9(60.0)$ & $20(74.1)$ & \\
\hline Skull fracture & $14(33.3)$ & $5(33.3)$ & $9(33.3)$ & 1.00 \\
\hline Skeletal fracture & $15(35.7)$ & $5(33.3)$ & $10(37.0)$ & 0.81 \\
\hline
\end{tabular}

Values are presented as number (\%).

$>2(18.5 \%)>5(14.8 \%)>4(7.4 \%)>3(3.7 \%)>0(0.0 \%) ;$ non-depressive group: FAC level $1(26.7 \%)>4(20.0 \%), 6$ $(20.0 \%)>2(13.3 \%), 3(13.3 \%)>5(6.7 \%) ; p=0.06)$. Other factors including linguistic performance and general cognition revealed no statistically significant associations with depressive mood.

Risk factors for depressive mood in geriatric TBI patients in the logistic regression analysis

Table 5 describes the results of the multifactorial binary logistic regression analysis for the risk factors that could affect depressive mood. The factors, including FIM total, FIM motor score, and mRS score were identified as statistically non-significant risk factors. Higher comorbidity score (odds ratio [OR], 1.764; 95\% confidence interval [CI], 1.047-2.971) was identified as a risk factor, considering the effects of the other factors. In comparison with right hemispheric lesions, bilateral hemispheric lesions (OR, 13.078; 95\% CI, 1.786-95.780) and left hemispheric lesions (OR, 46.074; 95\% CI, 3.175-668.502) were independently associated with depressive mood in the multiple logistic regression analysis.

\section{DISCUSSION}

In this study, a higher comorbidity score, lower FIM total score, lower FIM motor score, and higher mRS score were correlated with depressive mood in geriatric TBI patients. Elderly TBI patients with depressive mood had significantly more bilateral or left side brain injury than the non-depressive group. When the effects of the other factors were assessed, higher comorbidity score, bilateral lesion, and left side lesion were risk factors that had a correlation with depressive mood.

Few studies have investigated risk factors for depression after TBI, especially in geriatric patients. For posttraumatic young adult patients it has been reported that pre-injury unemployment $[20,21]$, poor social support $[3,22,23]$, lower education [24], pre-morbid psychiatric problems $[3,21,23,24]$, physical disabilities $[3,21]$, cognitive impairment [24], and frontal lobe lesion [23] are consistent predictors of depressive mood following brain injury. Age, sex [23], onset duration after injury [20,25], and severity of injury were inconclusive as risk factors for depressive mood after TBI. Injury severity itself does not predict the development of depression following TBI $[3,23,26]$. In our study, only subjects older than 60 years were recruited; hence, risk factors from previous research could not be considered as valid predictors for depression in elderly TBI. We found that lower education and cognitive impairment were not significantly different between the depressive group and non-depressive group. 
Table 4. Linguistic function, cognitive function, functional status and disability level of depressive and non-depressive geriatric patients after traumatic brain injury

\begin{tabular}{|c|c|c|c|c|}
\hline Variable & $\begin{array}{c}\text { Total } \\
(n=42)\end{array}$ & $\begin{array}{c}\text { Non-depressive group } \\
(n=15)\end{array}$ & $\begin{array}{c}\text { Depressive group } \\
(\mathbf{n}=\mathbf{2 7})\end{array}$ & p-value \\
\hline \multicolumn{5}{|l|}{ Linguistic function } \\
\hline Dysarthria & $17(40.5)$ & $9(60.0)$ & $8(29.6)$ & 0.06 \\
\hline Aphasia quotient (K-WAB) & $70.3 \pm 22.0$ & $71.6 \pm 22.3$ & $69.6 \pm 22.1$ & 0.91 \\
\hline Naming ability (K-BNT) & $24.4 \pm 13.5$ & $25.3 \pm 13.8$ & $23.8 \pm 13.6$ & 0.66 \\
\hline \multicolumn{5}{|l|}{ Cognitive function } \\
\hline K-MMSE & $18.3 \pm 5.0$ & $19.1 \pm 5.7$ & $17.9 \pm 4.6$ & 0.42 \\
\hline \multicolumn{5}{|l|}{ Functional status } \\
\hline \multicolumn{5}{|l|}{ FIM score } \\
\hline FIM-total & $58.6 \pm 27.1$ & $70.9 \pm 27.9$ & $51.8 \pm 24.6$ & $0.03^{*}$ \\
\hline FIM-motor & $40.0 \pm 21.7$ & $51.4 \pm 23.8$ & $33.7 \pm 17.8$ & $0.03^{*}$ \\
\hline FIM-cognitive & $19.0 \pm 8.2$ & $21.3 \pm 7.8$ & $17.7 \pm 8.3$ & 0.09 \\
\hline FAC & & & & 0.06 \\
\hline Level 1 & $19(45.2)$ & $4(26.7)$ & $15(55.6)$ & \\
\hline Level 2 & $7(16.7)$ & $2(13.3)$ & $5(18.5)$ & \\
\hline Level 3 & $3(7.1)$ & $2(13.3)$ & $1(3.7)$ & \\
\hline Level 4 & $5(11.9)$ & $3(20.0)$ & $2(7.4)$ & \\
\hline Level 5 & $5(11.9)$ & $1(6.7)$ & $4(14.8)$ & \\
\hline Level 6 & $3(7.1)$ & $3(20.0)$ & $0(0)$ & \\
\hline \multicolumn{5}{|l|}{ Disability level } \\
\hline mRS score & & & & $0.04^{*}$ \\
\hline 5 & $17(40.5)$ & $3(20.0)$ & $14(51.9)$ & \\
\hline 4 & $10(23.8)$ & $3(20.0)$ & $7(25.9)$ & \\
\hline 3 & $9(21.4)$ & $4(26.7)$ & $5(18.5)$ & \\
\hline 2 & $6(14.3)$ & $5(33.3)$ & $1(3.7)$ & \\
\hline 1 & $0(0)$ & $0(0)$ & $0(0)$ & \\
\hline 0 & $0(0)$ & $0(0)$ & $0(0)$ & \\
\hline
\end{tabular}

Values are presented as number (\%) or mean \pm standard deviation.

K-WAB, Korean version of the Western Aphasia Battery; K-BNT, Korean version of the Boston Naming Test; K-MMSE, Korean version of the Mini-Mental Status Examination; FIM, Functional Independence Measure; FAC, Functional Ambulation Classification; mRS, modified Rankin Scale.

${ }^{*} \mathrm{p}<0.05$.

Our study contained $57.2 \%$ highly educated subjects whose total years of education were more than 12 years. Traditionally, lower education level as a risk factor for depressive mood was interpreted as the determinant of lower socioeconomic status such as unemployment and low income. The findings from our study indicate that lower education level is less likely to impact the depressive mood of elderly people after retirement than that of young adults. Additional studies with a larger number of subjects are needed to confirm the results of our study.
Elderly TBI is known to be highly correlated with poor cognitive outcome. Although this study excluded subjects with severe cognitive deficit (K-MMSE scores $<10$ points), a high portion of cognitively impaired subjects with mean K-MMSE score of $18.3 \pm 5.0$ were included. Factors other than cognitive impairment could be stronger determinants for depressive mood in this study population.

This study found that higher dependency in activities of daily living with lower FIM total and motor scores correlated with depressive mood. In the same context, 
Table 5. Results of the multifactorial binary logistic regression analysis for risk factors of depressive mood in geriatric patients after traumatic brain injury

\begin{tabular}{lccc}
\hline \multicolumn{1}{c}{ Variable } & OR & 95\% CI & p-value \\
\hline Comorbidity score & 1.764 & $1.047-2.971$ & $0.03^{*}$ \\
FIM-total & 1.068 & $0.919-1.242$ & 0.39 \\
FIM-motor & 0.991 & $0.923-1.064$ & 0.80 \\
mRS score (\%) & & & \\
5 & 1.000 & & \\
4 & 0.560 & $0.048-6.462$ & 0.64 \\
3 & 0.439 & $0.037-5.145$ & 0.51 \\
2 & 0.039 & $0.002-1.004$ & 0.05 \\
Horizontal distribution & & & \\
\hline Right & 1.000 & & \\
\hline Left & 46.074 & $3.175-668.502$ & $0.005^{*}$ \\
Bilateral & 13.078 & $1.786-95.780$ & $0.01^{*}$ \\
\hline
\end{tabular}

OR, odds ratio; CI, confidence interval; FIM, Functional Independence Measure; mRS, modified Rankin Scale. ${ }^{*} \mathrm{p}<0.05$.

patients in the depressive group had significantly higher mRS scores, which means they had a higher degree of functional disability. Hart et al. [3] found that the development of depressive mood in the chronic stage following TBI was related to a lower FIM motor score. Bowen et al. [5] reported that better emotional status at 6 months post-injury was associated with less disability in everyday functioning at the same time point. Considering that the present study showed a trend similar to previous studies that targeted young adult subjects, functional limitation appears to be associated with depressive mood regardless of age.

The present results indicated that comorbidity could be correlated with depressive mood in elderly TBI. Subjects with higher comorbidity scores in our study had more frequent specific conditions such as myocardial infarction, congestive heart failure, uncomplicated diabetes, diabetes with end organ damage, and solid tumors. Previous studies in the general population have shown that medical illness was a well-established risk factor for depression [24,27]. Patients with any medical diagnosis were twice as likely to develop depression as patients without any medical diagnosis, which remains the same for the elderly group when they were examined separately [24]. It is only natural that the elderly have more numerous and diverse medical diseases than young healthy individuals, and our study confirmed the importance of comorbidity as a risk factor for depression in the elderly.

The horizontal distribution of the brain lesion was found herein to be correlated with depressive mood in geriatric patients after TBI. Several previous studies showed that depressive mood after acquired brain injuries was significantly associated with a left side lesion [2832]. Flor-Henry [33] and Silberman and Weingartner [34] suggested a complex model for the organization of mood. They proposed that emotions were better recognized by the right hemisphere, and control of emotional expression and related behaviors took place principally in the right hemisphere. They suggested a model of emotional control based on interactive inhibition between a right negatively biased and left positively biased hemisphere. Thus, according to they contralateral release hypothesis, euphoria resulted when the left hemisphere no longer received transcallosal neural inhibition from the right hemisphere, and depression resulted when the right hemisphere was released from inhibition by dysfunction in left hemisphere. Tucker [35] also suggested that the neural substrate for emotion was predominantly in the right hemisphere. Rather than emphasizing a contralateral release, however, he suggested ipsilateral release with right hemisphere dysfunction leading to positive mood, and left hemisphere dysfunction manifested as anxious, negative mood. Other studies $[28,34,36]$ have suggested that the left hemisphere did not appear to be 'released' by a right hemisphere lesion implying that the mechanism for depression was mediated within the left hemisphere. Particularly, left frontal hemisphere dysfunction may be expressed as the absence of approach motivation and the inability to experience pleasure. However, the details and the mechanisms of such lateralization models have yet to be elucidated, and further study is needed. Other studies $[37,38]$ have suggested that depression was likely involved in the disruption of a widely distributed and functionally interactive network of corticostriatal and corticolimbic pathways that are critical to the integrated regulation of mood. If a bilateral hemispheric lesion is considered to be a more widely disruptive brain lesion, then our findings could be compatible.

Previous studies have found that chronic pain is correlated with depressive mood in young-adult TBI $[39,40]$. Hoffman et al. [39] reported that the severity of depressive mood was related to pain intensity and interference. 
Sullivan-Singh et al. [40] suggested that moderate or more intense pain was associated with depressive mood in patients after TBI. However, since the present study included only elderly TBI patients (mean age was 69.6 years), used a different measurement tool for depression, and obtained the information on the presence of pain from the medical records by cross-sectional study which did not reflect the detailed characteristics of pain, no significant correlation was found between the two factors compared with previous studies.

This study has some limitations. First, it did not take into account differences of severity of TBI among the patients. There is a possibility of sample selection bias since we could not obtain information regarding initial Glasgow Coma Scale score, duration of loss of consciousness, duration of post traumatic amnesia from the medical records, and the study targeted patients hospitalized in a tertiary training hospital. Second, several limitations of the cross-sectional study design are also present. The data on each subject were simultaneously assessed making it difficult to infer the temporal association between a risk factor and an outcome. Considering that this crosssectional study evaluated prevalence rather than incident outcomes, and included subjects with different durations after injury and obscure onsets of depressive mood, a controlled longitudinal study is needed to make causal inference. Third, the number of subjects was small and unevenly distributed between the two groups. Further study with a prospective cohort design, large number of subjects, and a standardized diagnostic tool, such as the Diagnostic and Statistical Manual of Mental Disorders (DSM) criteria, is needed.

In conclusion, comorbidity, functional limitation, and location of brain injury, especially bilateral and left hemispheric injury, in geriatric patients with TBI could indicate a higher risk of developing depressive mood. During rehabilitation, post-TBI geriatric patients displaying these factors require careful observation of emotional changes for early detection and management.

\section{CONFLICT OF INTEREST}

No potential conflict of interest relevant to this article was reported.

\section{REFERENCES}

1. Pagulayan KF, Hoffman JM, Temkin NR, Machamer JE, Dikmen SS. Functional limitations and depression after traumatic brain injury: examination of the temporal relationship. Arch Phys Med Rehabil 2008;89:188792.

2. Menzel JC. Depression in the elderly after traumatic brain injury: a systematic review. Brain Inj 2008; 22:375-80.

3. Hart T, Hoffman JM, Pretz C, Kennedy R, Clark AN, Brenner LA. A longitudinal study of major and minor depression following traumatic brain injury. Arch Phys Med Rehabil 2012;93:1343-9.

4. Rapoport MJ, McCullagh S, Streiner D, Feinstein A. The clinical significance of major depression following mild traumatic brain injury. Psychosomatics 2003; 44:31-7.

5. Pudelek B. Geriatric trauma: special needs for a special population. AACN Clin Issues 2002;13:61-72.

6. Mushkudiani NA, Engel DC, Steyerberg EW, Butcher I, Lu J, Marmarou A, et al. Prognostic value of demographic characteristics in traumatic brain injury: results from the IMPACT study. J Neurotrauma 2007;24: 259-69.

7. Tokutomi T, Miyagi T, Ogawa T, Ono J, Kawamata T, Sakamoto T, et al. Age-associated increases in poor outcomes after traumatic brain injury: a report from the Japan Neurotrauma Data Bank. J Neurotrauma 2008;25:1407-14.

8. Hukkelhoven CW, Steyerberg EW, Rampen AJ, Farace E, Habbema JD, Marshall LF, et al. Patient age and outcome following severe traumatic brain injury: an analysis of 5600 patients. J Neurosurg 2003;99:666-73.

9. Levin HS, Goldstein FC, MacKenzie EJ. Depression as a secondary condition following mild and moderate traumatic brain injury. Semin Clin Neuropsychiatry 1997;2:207-15.

10. Oldfield RC. The assessment and analysis of handedness: the Edinburgh inventory. Neuropsychologia 1971; 9:97-113.

11. Charlson M, Szatrowski TP, Peterson J, Gold J. Validation of a combined comorbidity index. J Clin Epidemiol 1994;47:1245-51.

12. Charlson ME, Pompei P, Ales KL, MacKenzie CR. A new method of classifying prognostic comorbidity in 
longitudinal studies: development and validation. J Chronic Dis 1987;40:373-83.

13. Goldstein LB, Samsa GP, Matchar DB, Horner RD. Charlson Index comorbidity adjustment for ischemic stroke outcome studies. Stroke 2004;35:1941-5.

14. Thompson HJ, Weir S, Rivara FP, Wang J, Sullivan SD, Salkever D, et al. Utilization and costs of health care after geriatric traumatic brain injury. J Neurotrauma 2012;29:1864-71.

15. Kim H, Na DL. Normative data on the Korean version of the Western Aphasia Battery. J Clin Exp Neuropsychol 2004;26:1011-20.

16. Linacre JM, Heinemann AW, Wright BD, Granger CV, Hamilton BB. The structure and stability of the Functional Independence Measure. Arch Phys Med Rehabil 1994;75:127-32.

17. Holden MK, Gill KM, Magliozzi MR, Nathan J, PiehlBaker L. Clinical gait assessment in the neurologically impaired: reliability and meaningfulness. Phys Ther 1984;64:35-40.

18. van Swieten JC, Koudstaal PJ, Visser MC, Schouten $\mathrm{HJ}$, van Gijn J. Interobserver agreement for the assessment of handicap in stroke patients. Stroke 1988;19: 604-7.

19. Kim JY, Park JH, Lee JJ, Huh Y, Lee SB, Han SK, et al. Standardization of the Korean version of the geriatric depression scale: reliability, validity, and factor structure. Psychiatry Investig 2008;5:232-8.

20. Seel RT, Kreutzer JS, Rosenthal M, Hammond FM, Corrigan JD, Black K. Depression after traumatic brain injury: a National Institute on Disability and Rehabilitation Research Model Systems multicenter investigation. Arch Phys Med Rehabil 2003;84:177-84.

21. Bowen A, Neumann V, Conner M, Tennant A, Chamberlain MA. Mood disorders following traumatic brain injury: identifying the extent of the problem and the people at risk. Brain Inj 1998;12:177-90.

22. Rao V, Bertrand M, Rosenberg P, Makley M, Schretlen DJ, Brandt J, et al. Predictors of new-onset depression after mild traumatic brain injury. J Neuropsychiatry Clin Neurosci 2010;22:100-4.

23. Rapoport MJ. Depression following traumatic brain injury: epidemiology, risk factors and management. CNS Drugs 2012;26:111-21.

24. Alexopoulos GS. Editorial: geriatric depression in primary care. Int J Geriatr Psychiatry 1996;11:397-400.
25. Dikmen SS, Bombardier CH, Machamer JE, Fann JR, Temkin NR. Natural history of depression in traumatic brain injury. Arch Phys Med Rehabil 2004;85:1457-64.

26. Fann JR, Burington B, Leonetti A, Jaffe K, Katon WJ, Thompson RS. Psychiatric illness following traumatic brain injury in an adult health maintenance organization population. Arch Gen Psychiatry 2004;61:53-61.

27. Park M, Unutzer J. Geriatric depression in primary care. Psychiatr Clin North Am 2011;34:469-87.

28. Lipsey JR, Robinson RG, Pearlson GD, Rao K, Price TR. Mood change following bilateral hemisphere brain injury. Br J Psychiatry 1983;143:266-73.

29. Starkstein SE, Robinson RG, Price TR. Comparison of cortical and subcortical lesions in the production of poststroke mood disorders. Brain 1987;110(Pt 4):104559.

30. Fedoroff JP, Starkstein SE, Forrester AW, Geisler FH, Jorge RE, Arndt SV, et al. Depression in patients with acute traumatic brain injury. Am J Psychiatry 1992; 149:918-23.

31. Jorge RE, Robinson RG, Moser D, Tateno A, CrespoFacorro B, Arndt S. Major depression following traumatic brain injury. Arch Gen Psychiatry 2004;61:4250.

32. Starkstein SE, Robinson RG, Berthier ML, Parikh RM, Price TR. Differential mood changes following basal ganglia vs thalamic lesions. Arch Neurol 1988;45:72530.

33. Flor-Henry P. On certain aspects of the localization of the cerebral systems regulating and determining emotion. Biol Psychiatry 1979;14:677-98.

34. Silberman EK, Weingartner H. Hemispheric lateralization of functions related to emotion. Brain Cogn 1986;5:322-53.

35. Tucker DM. Lateral brain function, emotion, and conceptualization. Psychol Bull 1981;89:19-46.

36. Davidson RJ. Affective style and affective disorders: perspectives from affective neuroscience. Cogn Emot 1998;12:307-30.

37. Mayberg HS. Limbic-cortical dysregulation: a proposed model of depression. J Neuropsychiatry Clin Neurosci 1997;9:471-81.

38. Hudak A, Warner M, Marquez de la Plata C, Moore C, Harper C, Diaz-Arrastia R. Brain morphometry changes and depressive symptoms after traumatic brain injury. Psychiatry Res 2011;191:160-5. 
39. Hoffman JM, Pagulayan KF, Zawaideh N, Dikmen S, Temkin N, Bell KR. Understanding pain after traumatic brain injury: impact on community participation. Am J Phys Med Rehabil 2007;86:962-9.
40. Sullivan-Singh SJ, Sawyer K, Ehde DM, Bell KR, Temkin N, Dikmen S, et al. Comorbidity of pain and depression among persons with traumatic brain injury. Arch Phys Med Rehabil 2014;95:1100-5. 